\title{
Chemical Polymerization of Aniline in Hydrochloric Acid (HCl) and Formic Acid (HCOOH) Media. Differences Between the Two Synthesized Polyanilines
}

\author{
E. C. Gomes", M. A. S. Oliveira \\ Instituto Tecnológico de Aeronáutica (ITA), Chemistry Department and Aeronautics-Mechanics Division, Gas Turbine Reference \\ Center, Pça, Mal Eduardo Gomes, 50 - CTA, São José dos Campos, SP, CEP 12 228-900, Brazil
}

\begin{abstract}
Conductive polyaniline (doped PAni) was synthesized by a chemical method in media containing, respectively, hydrochloric $(\mathrm{HCl})$ and formic acid $(\mathrm{HCOOH})$. The FT-IR and Raman results showed that the doping degree of PAni-HCOOH is greater than that of the PAni-HCl. Additionally, the Raman studies indicated that the oxidation degree of $\mathrm{PAni}-\mathrm{HCOOH}$ is higher than that of $\mathrm{PAni}-\mathrm{HCl}$, and that polaron segments dominate the PAni-HCOOH structure. The thermogravimetric analysis (TGA) in oxidizing atmosphere also suggests that the doping level of PAni with HCOOH is higher than that of PAni with $\mathrm{HCl}$. The DSC results confirm the differences of the thermal degradation mechanism, in non oxidative atmosphere, of the polymeric chain of both polyanilines. The electrical conductivity of the PAni-HCOOH was 7.51 $\mathrm{S} \mathrm{cm}^{-1}$, while that of the PAni-HCl was $0.143 \mathrm{~S} \mathrm{~cm}^{-1}$ confirming the results of FT-IR, Raman and TGA, i.e., the oxidation and the doping degree of PAni-HCOOH is higher than that of PAni-HCl.
\end{abstract}

Keywords PAni-HCl, PAni-HCOOH, Thermal analyses

\section{Introduction}

Conducting polymers, polyaniline (PAni) among them, alone or mixed with conventional polymers, have been successfully applied in batteries[1], sensors[2], electrochromic devices, capacitors[3], solar cells, corrosion inhibitors, light emitting diodes, metallization[4], coating for metallic surfaces, etc[5-9]. The extensive range of applications of polyaniline can be ascribed to its ease of synthesis, reduced processing cost, chemical stability, and conductivity, which can be as high as 10 to $10^{3} \mathrm{~S} \mathrm{~cm}^{-1}[10-16]$.

Polyaniline can be synthesized by electrochemical methods (potentiostatically or galvanostatically), by oxidation of the monomer using inert electrodes, such as stainless steel, platinum, gold, different types of carbon (vitreous or pyrolytic graphite), and glass covered with metal oxides[6]. Polyaniline can also be chemically synthesized in acidic media using an oxidizing agent, such as potassium dichromate, ammonium persulfate, hydrogen peroxide, cerium nitrate, etc[6].

PAni exists in three different forms: leucoemeraldine base (LEB, fully reduced form), emeraldine base (EB, partially oxidized form) and base Pernigraniline (PNB, fully oxidized form[17].

* Corresponding author:

evertonquimica@gmail.com (E. C. Gomes)

Published online at http://journal.sapub.org/ajps

Copyright (C) 2012 Scientific \& Academic Publishing. All Rights Reserved
Among the different oxidation states of PAni, the emeraldine salt (ES) is the only one that presents electrical conductivity. Nonetheless, the emeraldine base (EB) can be converted to emeraldine salt (ES), and vice-versa, by protonation/ deprotonation with acid/base, as depicted in Figure $1[18]-19]$.

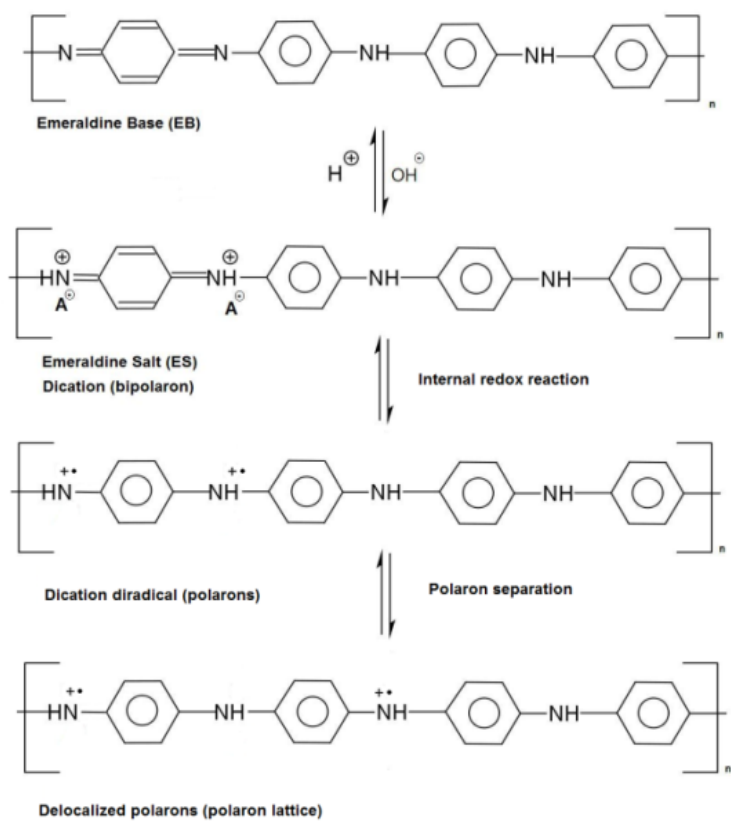

Figure 1. Doping and de-doping processes of polyaniline (PAni) (Adaptation of $[20,21])$ and Mechanism of formation of polaron structure of polyaniline (Adaptation of[22]) 
In this work the synthesis of polyaniline in its doped state, in hydrochloric acid (PAni-HCl) and formic acid (PAni$\mathrm{HCOOH}$ ) media, was studied. Thermogravimetric analysis (TGA) and differential scanning calorimetry (DSC) were used to study the thermal stability of the doped polyanilines. Infrared absorption (FT-IR) and Raman scattering were used to investigate composition changes of the corresponding emeraldine salts, (PAni-HCl and $\mathrm{PAni}-\mathrm{HCOOH})$, due to the synthesis process.

\section{Experimental}

\subsection{Synthesis of Polyaniline Doped with Hydrochloric Acid (HCl)}

Doped polyaniline (PAni- $\mathrm{HCl})$ was chemically synthesized[23-24] using aniline, previously distilled under vacuum, and ammonium persulfate $\left(\left(\mathrm{NH}_{4}\right)_{2} \mathrm{~S}_{2} \mathrm{O}_{8}\right)$ as oxidant in a 4:1 monomer/oxidant molar ratio. $20 \mathrm{~mL}$ of the previously distilled aniline was dissolved in $40 \mathrm{~mL}$ of $1 \mathrm{~mol} \mathrm{~L}^{-1}$ aqueous solution of hydrochloric acid in a $250 \mathrm{~mL}$ flask. During the dissolution the flask was kept inside a vessel containing a mixture of ice and salt at a temperature of $\sim-10^{\circ} \mathrm{C}$. Separately, $12 \mathrm{~g}$ of $\left(\mathrm{NH}_{4}\right)_{2} \mathrm{~S}_{2} \mathrm{O}_{8}$ was dissolved in $160 \mathrm{~mL}$ of $1 \mathrm{~mol}$ $\mathrm{L}^{-1}$ hydrochloric acid aqueous solution. The acid solution of $\left(\mathrm{NH}_{4}\right)_{2} \mathrm{~S}_{2} \mathrm{O}_{8}$ was slowly and carefully added into the flask containing the aniline acid solution during a period of $2 \mathrm{~h}$ and under constant stirring. During this entire process, the reaction medium was kept in $\sim-10{ }^{\circ} \mathrm{C}$. The reaction medium changed color, going through tons of brown, blue and green, and a solid deposit was formed at the bottom of the reaction flask. The green sediment was filtered, rinsed with a $1 \mathrm{~mol}$ $\mathrm{L}^{-1} \mathrm{HCl}$ solution and dried under dynamic vacuum at room temperature for $72 \mathrm{~h}$. Under these conditions the polymer obtained is in a doped state $(\mathrm{PAni}-\mathrm{HCl})$ slightly soluble in water[21].

\subsection{Synthesis of Polyaniline Doped with Formic Acid (HCOOH)}

Aniline was polymerized in formic acid $(\mathrm{HCOOH})$ medium using $\left(\mathrm{NH}_{4}\right)_{2} \mathrm{~S}_{2} \mathrm{O}_{8}$ as oxidizing agent. In a typical procedure, $1 \mathrm{~mL}(0.0107 \mathrm{~mol})$ of previously distilled aniline was dissolved in $25 \mathrm{~mL} \mathrm{HCOOH} \mathrm{(85 \%} \mathrm{weight)} \mathrm{at} \mathrm{room}$ temperature[26]. The obtained solution was cooled to about $2{ }^{\circ} \mathrm{C}$ in an ice bath. A solution of $2.44 \mathrm{~g}(0.0107 \mathrm{~mol})$ $\left(\mathrm{NH}_{4}\right)_{2} \mathrm{~S}_{2} \mathrm{O}_{8}$ dissolved in $25 \mathrm{~mL} \mathrm{HCOOH} \mathrm{(85 \%} \mathrm{weight)} \mathrm{was}$ added dropwise into the cold aniline acid solution under constant stirring over a period of $30 \mathrm{~min}$. The mixture was stirred over additional $2 \mathrm{~h}$ and its temperature was kept in 2 ${ }^{\circ} \mathrm{C}$ during this period. At the end of this period of time a dark green solid was formed in the reaction medium. This solid was filtered, thoroughly rinsed with deionized water and methanol. Under these conditions the polymer is obtained in a doped state (PAni-HCOOH).

\subsection{Infrared Spectroscopy (FT-IR)}

The compositions of the synthesized PAnis were characterized by infrared spectroscopy (FT-IR). $\mathrm{KBr}$ pellets were prepared for both, PAni-HCl and PAni-HCOOH. These pellets were used to obtain the FT-IR spectra in the range of $2000-500 \mathrm{~cm}^{-1}$, performing 20 scans with a resolution of 4 $\mathrm{cm}^{-1}$. The spectrometer used in this study was a Perkin Elmer, Spectrum One type spectrometer.

\subsection{Raman Spectroscopy}

Raman spectroscopy was used as a complement to characterize the composition of the synthesized polyanilines. A spectrophotometer Renishow model 2000 Raman was utilized for data acquisitions. Samples, in the powder form, were excited with a $514.5 \mathrm{~nm}$ Argon laser $(0.5 \mathrm{~mW})$, using a Spectra Physics equipment, model 127. 10 acquisitions of 10 $\mathrm{s}$ each were used to obtain every spectrum. All Raman data acquisitions were obtained at room temperature $\left( \pm 25^{\circ} \mathrm{C}\right)$.

\subsection{Thermogravimetric Analysis (TGA)}

Thermogravimetric analysis (TGA) of the synthesized polyanilines was performed using a TGA-51 Shimadzu in the temperature range of 30 to $1000^{\circ} \mathrm{C}$, under $\mathrm{N} 2$ and air

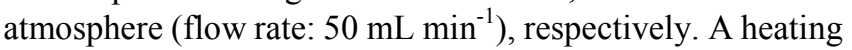
rate of $10^{\circ} \mathrm{C}$ was used during the TGA tests. A crucible of platinum containing $15 \mathrm{mg}$ of sample was used in the TGA analysis.

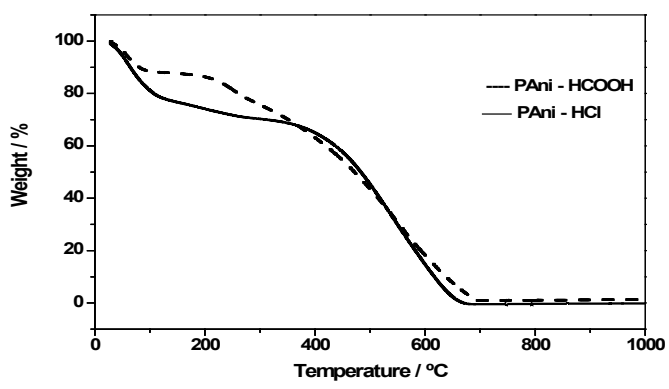

(a)

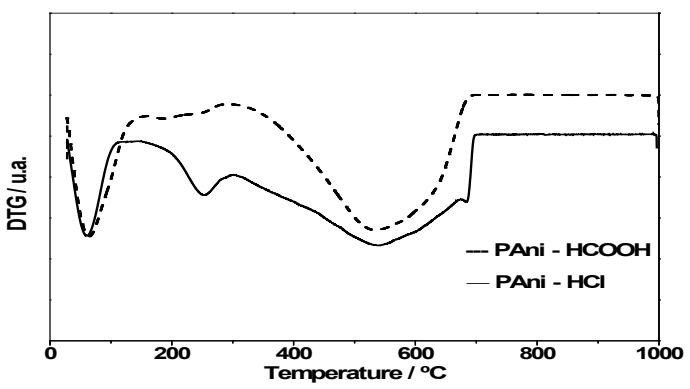

(b)

Figure 2. (a) TGA and (b) DTG of PAni-HCl and PAni-HCOOH in oxidant atmosphere (air) $\left(10^{\circ} \mathrm{C} \mathrm{min}^{-1}\right)$

\subsection{Differential Scanning Calorimetry (DSC)}

Differential scanning calorimetry (DSC) was carried out on a Netzch DSC 404 Pegasus in the temperature range of 25 
to $590{ }^{\circ} \mathrm{C}$, under helium atmosphere (flow rate: $50 \mathrm{~mL} \mathrm{~min}^{-1}$ ). The heating rate was $20^{\circ} \mathrm{C} \mathrm{min}-1$. A crucible of aluminum containing $15 \mathrm{mg}$ of sample was used in the DSC analysis.

\subsection{Electrical Conductivity}

Electrical conductivity measurements were made using a Cascade Microtech C4S-64 four probe system coupled to a source (Keithley 236), a multimeter and an ammeter. Circular plaque samples, $\sim 2 \mathrm{~mm}$ thick and with $15 \mathrm{~mm}$ of diameter, were prepared by uniaxial pressing.

\section{Results and Discussion}

\subsection{Thermogravimetric analyses (TGA) and Differential Scanning Calorimetry (DSC)}

The results of TGA and DTG (first derivative of TGA curves) for samples of doped polyanilines (PAni- $\mathrm{HCl}$ and $\mathrm{PAni}-\mathrm{HCOOH}$ ), in an atmosphere of air, are showed in Figure 2.

At temperatures lower than $120{ }^{\circ} \mathrm{C}$, PAni-HCOOH presents a weight loss of $\sim 12 \% \mathrm{wt}$, much smaller than that of PAni-HCl ( 23\% wt) (Figures $2 \mathrm{a}$ and $2 \mathrm{~b})$. The weight loss in this temperature range has been attributed to volatilization of water absorbed by the polymer in the form of moisture[26-27]. In this case, one can infer that the absorption of water by the $\mathrm{PAni}-\mathrm{HCl}$ is greater than that of the PAni-HCOOH.

In the temperature range of $85-215^{\circ} \mathrm{C}, \mathrm{PAni}-\mathrm{HCOOH}$ loses about $2 \%$ of its weight and $\sim 19 \%$ wt more between $210-365{ }^{\circ} \mathrm{C}$, losing in total $\sim 21 \%$ of its weight in the temperature range of $85-365{ }^{\circ} \mathrm{C}$. PAni- $\mathrm{HCl}$ loses $\sim 7 \%$ of its weight between about 105 and $260{ }^{\circ} \mathrm{C}$ and another $\sim 4 \%$ wt between $\sim 260-365{ }^{\circ} \mathrm{C}$, losing in total $\sim 11 \%$ of its weight in the temperature range of $85-365^{\circ} \mathrm{C}$.

The thermal stability of polyaniline in the temperature range of 85 to $215^{\circ} \mathrm{C}$ has been attributed to the formation of cross-linking bonds during heating, a process that involves no weight loss[28-30]. Weight losses of doped polyaniline at temperatures varying from 90 to $250{ }^{\circ} \mathrm{C}$ have also been attributed to loss of water linked to the polymer structure as a dopant[31]. Therefore, the thermal stabilization observed for $\mathrm{PAni}-\mathrm{HCOOH}$ in this temperature range (only $\sim 2 \%$ of weight loss) could be attributed to formation of cross-linking bonds during the heating process, while the weight loss observed for PAni-HCl $(\sim 7 \%$ wt) would be attributed to vaporization of water present in this polymer as a dopant. The presence of formic acid as a dopant in the polymer structure contributes for its structure stabilization at the temperature range of $85-215^{\circ} \mathrm{C}$ in oxidative atmosphere.

The additional weight loss observed for PAni-HCOOH ( $19 \% \mathrm{wt}$ ) between 210 and $365^{\circ} \mathrm{C}$ was greater than the one observed for the PAni-HCl ( 4\% wt) between 260 and 365 ${ }^{\circ} \mathrm{C}$. Weight losses observed for polyanilines in this temperature range have been attributed to evolution of the dopant and/or smaller chain oligomers[31-32]. The fact that
PAni-HCOOH loses a greater weight than PAni-HCl in this temperature range suggests the doping level of PAni with $\mathrm{HCOOH}$ is higher than that of PAni with $\mathrm{HCl}$.

For temperatures higher than $\sim 365{ }^{\circ} \mathrm{C}$, a significant weight loss takes place for both polyanilines. PAni-HCOOH loses $\sim 64 \%$ wt in temperatures between 430 and $675{ }^{\circ} \mathrm{C}$, while PAni-HCl loses $\sim 66 \%$ of its weight between 430 and $650{ }^{\circ} \mathrm{C}$. Weight losses in this temperature range have been attributed to thermal decomposition of the main molecular chain of the polymer[31].

The TGA and DTG (first derivative of TGA curves) results for $\mathrm{PAni}-\mathrm{HCl}$ and $\mathrm{PAni}-\mathrm{HCOOH}$ in inert atmosphere $\left(\mathrm{N}_{2}\right)$ are showed in Figure 3.

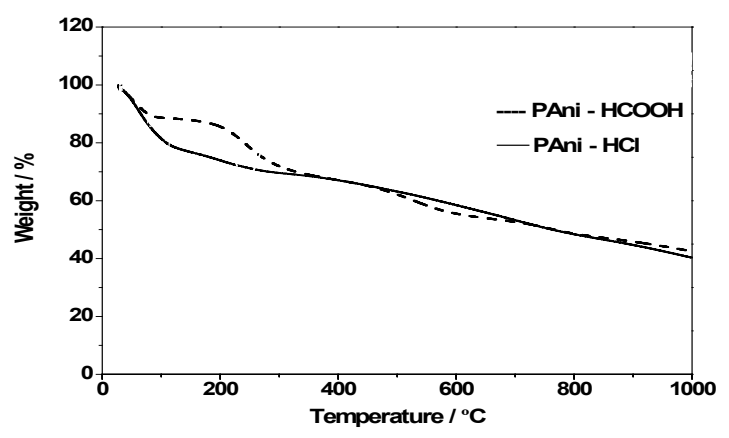

(a)

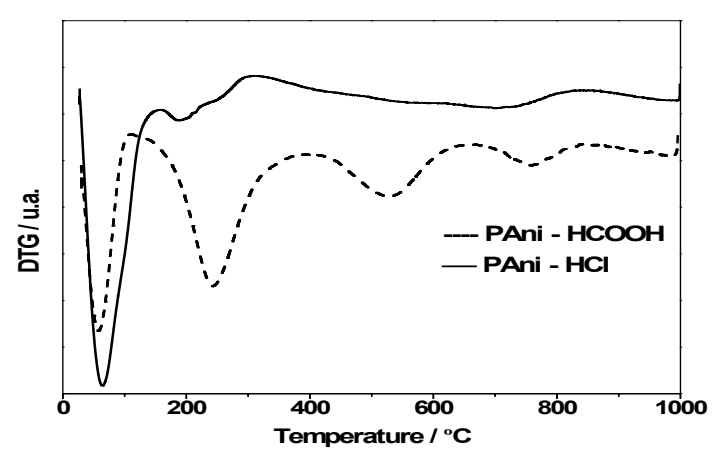

(b)

Figure 3. (a) TGA and (b) DTG of doped polyaniline (PAni-HCl) and $(\mathrm{PAni}-\mathrm{HCOOH})$ in an inert atmosphere $\left(\mathrm{N}_{2}\right)\left(10^{\circ} \mathrm{C} \mathrm{min}^{-1}\right)$

Contrasting with the thermal behavior in oxidative (air) atmosphere, at which the doped PAnis were completely destroyed by oxidative changes at temperatures around 700 ${ }^{\circ} \mathrm{C}$, in nitrogen atmosphere, carbonization takes place leaving a marked amount of residue $(47 \% \mathrm{wt})[23]$.

In $\mathrm{N}_{2}$ atmosphere and temperatures lower than $100^{\circ} \mathrm{C}$, the weight loss of PAni-HCOOH $(\sim 11 \% \mathrm{wt})$ is smaller than that observed for PAni-HCl $(\sim 21 \% \mathrm{wt})$. The weight loss of polyaniline in this temperature range has been attributed to the volatilization of water in the form of moisture absorbed by the polymer[26-27, 32-35] and it is hardly influenced by oxidative or inert atmosphere. These results confirm that the water absorption by $\mathrm{PAni}-\mathrm{HCl}$ is much greater than that absorbed by PAni-HCOOH.

In $\mathrm{N}_{2}$ atmosphere, PAni-HCOOH loses $2 \%$ wt between 
$90-185^{\circ} \mathrm{C}$, plus $17 \%$ wt between $185-325^{\circ} \mathrm{C}$ and more $5 \%$ wt between 325 and $450{ }^{\circ} \mathrm{C}$, losing a total of $24 \%$ wt, against $21 \% \mathrm{wt}$ in air. PAni-HCl loses $3 \%$ wt between 110 and 165 ${ }^{\circ} \mathrm{C}, 6 \%$ wt more between $165-255{ }^{\circ} \mathrm{C}$, and additional $5 \%$ between 255 and $450{ }^{\circ} \mathrm{C}$, making a total of $14 \%$ wt, against $11 \%$ wt in air. In this temperature range $\left(\sim 100-450{ }^{\circ} \mathrm{C}\right)$, the weight loss in inert atmosphere is a little higher than in oxidative atmosphere, but the thermal processes are practically the same, i.e., PAni-HCl loses water linked to the polymer structure and dopant, while PAni-HCOOH changes its structure and loses dopant $[32,33,36]$.

Significantly different from what occurs in oxidative atmosphere, the DTG curves show that, between 310 and 850 ${ }^{\circ} \mathrm{C}$, at least one stage is involved in the thermal degradation process of $\mathrm{PAni}-\mathrm{HCl}$, while two well defined stages, peaks with maximum at 530 and $760{ }^{\circ} \mathrm{C}$, respectively, are involved in the thermal degradation of PAni-HCOOH between 390 and $850^{\circ} \mathrm{C}$. PAni- $\mathrm{HCl}$ loses $17 \%$ of its weight in the temperature range of $450-805{ }^{\circ} \mathrm{C}$, while $\mathrm{PAni}-\mathrm{HCOOH}$ loses $10 \%$ of its weight between 450 and $605{ }^{\circ} \mathrm{C}, 3 \%$ wt more between 605 and $702{ }^{\circ} \mathrm{C}$, and plus $5 \%$ wt between 702 and $820{ }^{\circ} \mathrm{C}$, losing $18 \% \mathrm{wt}$ in total in the temperature range of $450-820^{\circ} \mathrm{C}$.

Thermal decomposition studies of doped polyaniline in non-oxidative atmosphere (He) using DSC $\backslash$ TGA $\backslash M S$ reveled that in temperatures between 450 and over $700{ }^{\circ} \mathrm{C}$ the polymer chain break involves the following stages: elimination of many small fragments at $450{ }^{\circ} \mathrm{C}$; elimination of aromatic fragments and decarboxylation of extended aromatic structures, with $\mathrm{CO}_{2}$ evolution and formation of coke at $550{ }^{\circ} \mathrm{C}$, and decomposition of the residue with elimination of substituted aromatic fragments and graphitization at temperatures over $655{ }^{\circ} \mathrm{C}[37]$. These three stages of polymer chain break are quite evident in the thermal degradation of PAni-HCOOH in non oxidative atmosphere and temperatures superior to $450{ }^{\circ} \mathrm{C}$, but they are not clear in the thermal degradation of PAni-HCl. It seems that PAni-HCl does not degrade into small fragments as $\mathrm{PAni}-\mathrm{HCOOH}$ seems to do, but in temperatures superior to $310{ }^{\circ} \mathrm{C}$ its chain might gradually break into more extended aromatic fragments that suffer further decarboxylation and graphitization at temperatures over $700{ }^{\circ} \mathrm{C}$, as observed in those DSC $\backslash \mathrm{TGA} \backslash \mathrm{MS}$ studies for doped polyaniline[37]. This suggestion is supported in this work by the fact that the residual amount of $\mathrm{PAni}-\mathrm{HCl}$ is higher than that of $\mathrm{PAni}-\mathrm{HCOOH}$ in temperatures between 450 and $700{ }^{\circ} \mathrm{C}$. Since the thermal stability of intrinsically oxidized PAni is dependent of the dopant acid and generally decreases with the doping degree[38], the behavior of $\mathrm{PAni}-\mathrm{HCl}$ in the temperature range starting from 310 up to $850{ }^{\circ} \mathrm{C}$ might be a consequence of its smaller doping degree in comparison with that of PAni-HCOOH. $\mathrm{PAni}-\mathrm{HCOOH}$, on the other hand, might break into small fragments in temperatures between 390 and $650{ }^{\circ} \mathrm{C}$, with formation of aromatic and substituted aromatic segments, which decarboxylate and graphitize at temperatures around 650 and $700{ }^{\circ} \mathrm{C}$, respectively, as was observed in those DSC $\backslash T G A \backslash M S$ studies for doped polyanilines mentioned before[37]. Despite of these differences in the thermal degradation mechanism of the polymeric chain, both PAni-HCl and PAni-HCOOH synthesized in this work present practically the same residual weight at temperatures around 850 ${ }^{\circ} \mathrm{C}$.

The TGA (in $\mathrm{N}_{2}$ ) and DSC (in $\mathrm{He}$ ) results for PAni-HCl and PAni-HCOOH are showed in Figure 4.

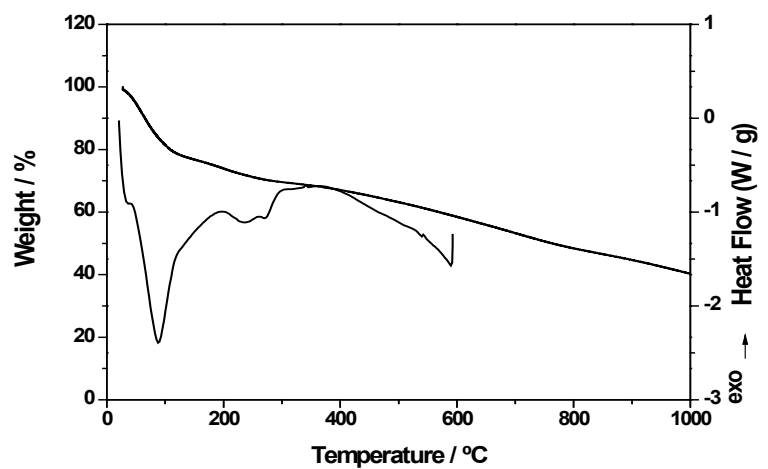

(a)

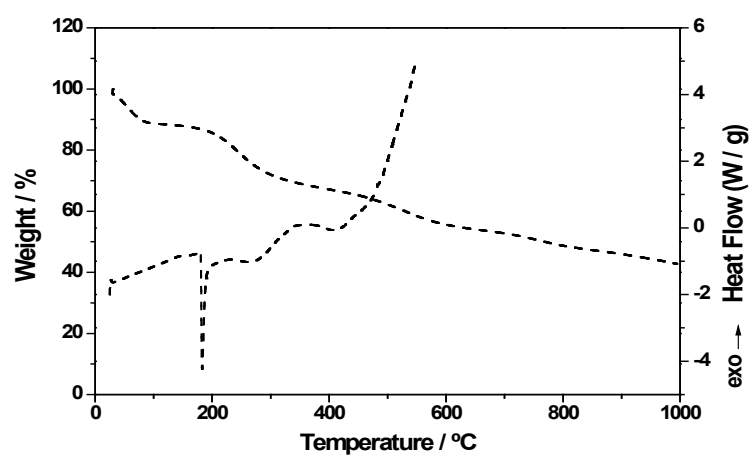

(b)

Figure 4. DSC, in helium $\left(20^{\circ} \mathrm{C} \mathrm{min}^{-1}\right)$ atmosphere, and TGA, in nitrogen $\left(10^{\circ} \mathrm{C} \mathrm{min}{ }^{-1}\right)$ atmosphere, of (a) PAni- $\mathrm{HCl}$ and (b) PAni-HCOOH

The DSC of PAni-HCl presents a very intense endothermic peak at $88^{\circ} \mathrm{C}$ (Figure 4 (a)). This peak can be associated to the evolution of water in the form of moisture absorbed by the polymer, which was observed in the TGA curve at temperatures lower than $100^{\circ} \mathrm{C}$. Two less intense endothermic peaks appear, respectively at 235 and $270{ }^{\circ} \mathrm{C}$, in the DSC thermogram of PAni-HCl. The peak $235{ }^{\circ} \mathrm{C}$ can be associated to evaporation of water linked to the polymer chain as dopant, as observed in the TGA curve o this polymer at temperatures between 90 and $250{ }^{\circ} \mathrm{C}$, while that peak at 270 ${ }^{\circ} \mathrm{C}$ can be associated to the loss of the dopant observed in the TGA experiments in temperatures between 260 and $365^{\circ} \mathrm{C}$. From 370 up to $590{ }^{\circ} \mathrm{C}$ a new endothermic process starts, which can be associated to the beginning of the polymer chain break into extended aromatic fragments, as ascribed to the weight loss observed for this polymer in temperatures superior to $310^{\circ} \mathrm{C}$ in the TGA results of this polymer.

Figure 4 (b) shows de DSC $(\mathrm{He})$ and the TGA $\left(\mathrm{N}_{2}\right)$ results for PAni-HCOOH. The DSC curve shows a very intense 
endothermic peak at $\sim 183{ }^{\circ} \mathrm{C}$, which can be related to the structural changes observed in the TGA results in temperatures between 85 and $215{ }^{\circ} \mathrm{C}$ that provides thermal stabilization to $\mathrm{PAni}-\mathrm{HCOOH}$ in this temperature range. A second endothermic peak of low intensity appears at $\sim 261{ }^{\circ} \mathrm{C}$. This peak can be associated to evolution of the dopant[35], as ascribed to the weight losses observed in the TGA thermogram in temperatures between 185 and $325^{\circ} \mathrm{C}$. A third endothermic peak appears at $405{ }^{\circ} \mathrm{C}$ of the DSC thermogram. This peak does not appear in the DSC thermogram of PAni-HCl. It can be associated to the break of the PAni-HCOOH chain into small fragments ascribed to the thermal degradation process that was observed in the TGA results in temperatures between 390 and $650{ }^{\circ} \mathrm{C}$. Above 450 ${ }^{\circ} \mathrm{C}$ up to $550{ }^{\circ} \mathrm{C}$, an exothermic process takes place, which was not observed in the DSC results of PAni-HCl. This exothermic process can be associated to the subsequent formation of aromatic and substituted aromatic segments, from the small fragments formed in the previous stage of the thermal degradation of the PAni-HCOOH, ascribed to the thermal degradation processes occurring in temperatures between 390 and $605{ }^{\circ} \mathrm{C}$ in the TGA analysis. These two last observations confirm the differences in the thermal degradation mechanism of the two polyanilines prepared in this work.

\subsection{Spectral Analysis (FT-IR)}

Figure 5 shows the FT-IR spectra of $\mathrm{PAni}-\mathrm{HCl}$ and PAni-HCOOH.

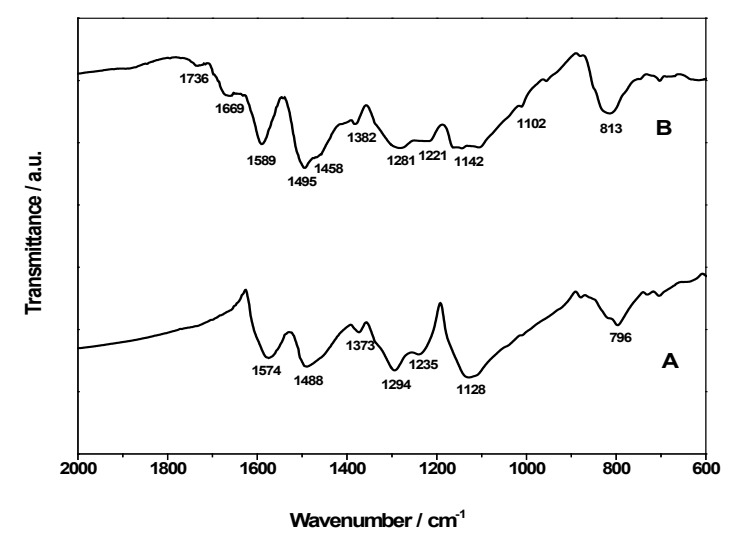

Figure 5. FT-IR spectrum of (A) PAni-HCl and (B) PAni-HCOOH

The bands with maximum in 1574 and $1488 \mathrm{~cm}^{-1}$ in the spectrum of $\mathrm{PAni}-\mathrm{HCl}$ are assigned to stretching vibrations of quinoid ring $(\mathrm{Q})$ and benzenoid $(\mathrm{B})$, respectively. The ratio of the maximum intensity these two bands $\left(\mathrm{I}_{\mathrm{Q}} / \mathrm{I}_{\mathrm{B}}\right)$ can be used to estimate the degree of oxidation on polyaniline[39]. The bands assigned to the stretching of the quinoid ring (Q) and benzenoid (B) also appear in the spectrum of PAni- $\mathrm{HCOOH}$, in 1589 and $1495 \mathrm{~cm}^{-1}$, respectively. The $\mathrm{I}_{\mathrm{Q}}$ $/ \mathrm{I}_{\mathrm{B}}$ ratio of these two bands in the FT-IR spectrum of $\mathrm{PAni}-\mathrm{HCOOH}$ is similar to that in the spectrum of PAni- $\mathrm{HCl}$, indicating that, apparently, the oxidation degree of
PAni-HCOOH is somewhat similar to that of PAni-HCl.

The spectrum of PAni-HCl has a small intensity band at $1373 \mathrm{~cm}^{-1}$, which is attributed to stretching of $\mathrm{C}-\mathrm{N}$ bonds next to a quinoid ring $(\mathrm{C}-\mathrm{N}=\mathrm{Q}=\mathrm{N}-\mathrm{C})$. The band at 1294 $\mathrm{cm}^{-1}$ in this spectrum is attributed to stretching of $\mathrm{C}-\mathrm{N}$ bonds of secondary aromatic amines[31] and / or displacement of $\pi$ electrons, induced by acid doping of the polymer. The band characteristic of the electrically conductive form of doped polyanilines is observed at $1235 \mathrm{~cm}^{-1}$ in the FT-IR spectrum of PAni-HCl. This band is attributed to the stretching of the $\mathrm{C}-\mathrm{N}^{+\bullet}$ polaron structure, formed as a result of the acid doping of the emeraldine base (EB) form of polyaniline, as schematically depicted in Figure 1[23]. The band at $1128 \mathrm{~cm}^{-1}$ is the most intense in the PAni- $\mathrm{HCl}$ (Figure 5 A) FT-IR spectrum and is attributed to vibration of the $\mathrm{NH}^{+}=$structure formed in the acid doping process of polyaniline, Figure 1.

The band, corresponding to the movement of $\pi$ electrons induced by doping the polymer $\left(1281 \mathrm{~cm}^{-1}\right)$, also appears in the spectrum of PAni-HCOOH. It appears shifted to lower wavernumber in relation to that of the corresponding band in the spectrum of PAni-HCl. This suggests that, the doping degree of the PAni-HCOOH might be greater than that of the $\mathrm{PAni}-\mathrm{HCl}$, which favors the movement of $\pi$ electrons and justifies the displacement of the corresponding band to lower wavernumber. This last suggestion is reinforced by the finding that in the spectrum of $\mathrm{PAni}-\mathrm{HCOOH}$ the ration between the intensity of the band in $1221 \mathrm{~cm}^{-1}$, assigned to $\mathrm{C}$ $-\mathrm{N}^{+\bullet}$ stretching of the polaron structure (Figure 1), and that of the band at $1281 \mathrm{~cm}^{-1}$, corresponding to the delocalization of $\pi$ electrons, is greater than the ratio of the intensity of the same bands in the spectrum of the PAni-HCl. Additionally, the band assigned to $-\mathrm{NH}^{+}=$vibrations, band in $1142 \mathrm{~cm}^{-1}$, in the spectrum of PAni-HCOOH is also one of the most intense in this spectrum. Therefore, these FT-IR results agree with the thermogravimetric analysis (TGA) in oxidizing atmosphere, which also suggests that the doping level of PAni with $\mathrm{HCOOH}$ is higher than that of PAni with $\mathrm{HCl}$.

The region between $900-700 \mathrm{~cm}^{-1}$ corresponds to aromatic ring deformation and $\mathrm{C}-\mathrm{H}$ bond vibrations out of ring plane[21].

The presence of formate anions in the PAni-HCOOH structure is indicated by the appearance of the peaks in 1736 and $1669 \mathrm{~cm}^{-1}$, assigned respectively to vibration of carboxyl groups and $\mathrm{C}=\mathrm{O}[26]$.

\subsection{Spectral Analysis (Raman)}

Fig. 6 shows the Raman spectra of doped PAni-HCl and PAni - $\mathrm{HCOOH}$.

To facilitate the interpretation of the results, the Raman spectra of polyaniline obtained in this work (PAni-HCl and $\mathrm{PAni}-\mathrm{HCOOH}$ ) were splited in three regions of wavenumber: I) region corresponding to $\mathrm{C}-\mathrm{C}$ ring stretching vibrations, between 1650 and $1520 \mathrm{~cm}^{-1}$, II) region at which the different $\mathrm{C}-\mathrm{N}$ stretch modes prevail, between 1520 and $1210 \mathrm{~cm}^{-1}$, and III) region corresponding to the deformation of $\mathrm{C}-\mathrm{H}$ 
bond, between 1210 and $1100 \mathrm{~cm}^{-1}$.

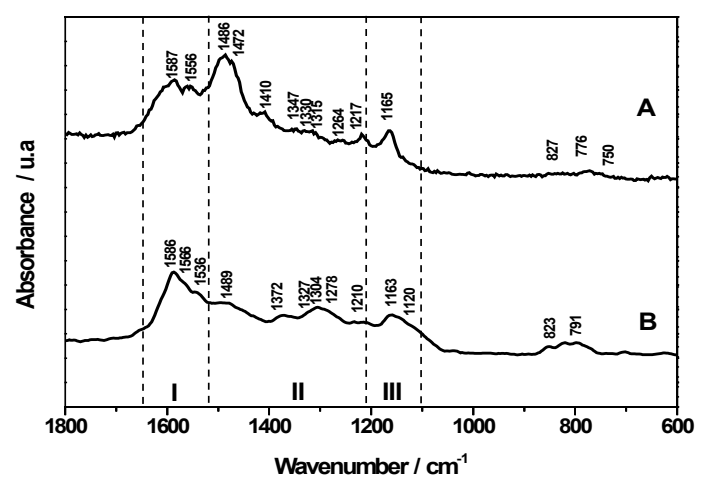

Figure 6. Raman spectrum of (A) PAni-HCl and (B) PAni-HCOOH. emeraldine salt; EB: emeraldine base; PB: pernigraniline base (Adaptation of[41])

The Raman spectra of PAni-HCl and PAni-HCOOH show a peak at $\sim 1165 \mathrm{~cm}^{-1}$, which has been attributed to the deformation of the $\mathrm{C}-\mathrm{H}$ bond in the ring plane of bipolaron structures[40]. This way, one can say that both polyanilines obtained in this study show segments of bipolaron structure in the polymer chain.

Only the spectrum of PAni-HCOOH shows a peak at $1120 \mathrm{~cm}^{-1}$, which appears as a shoulder in this spectrum. This peak is usually attributed to in plane deformations of $\mathrm{C}-\mathrm{H}$ ring bonds in structures containing appreciable amount of segments of the more oxidized Pernigraniline base form (Figure 7)[40]. Therefore, one can say that the oxidation degree of $\mathrm{PAni}-\mathrm{HCOOH}$ is, in fact, higher than that of PAni-HCl.

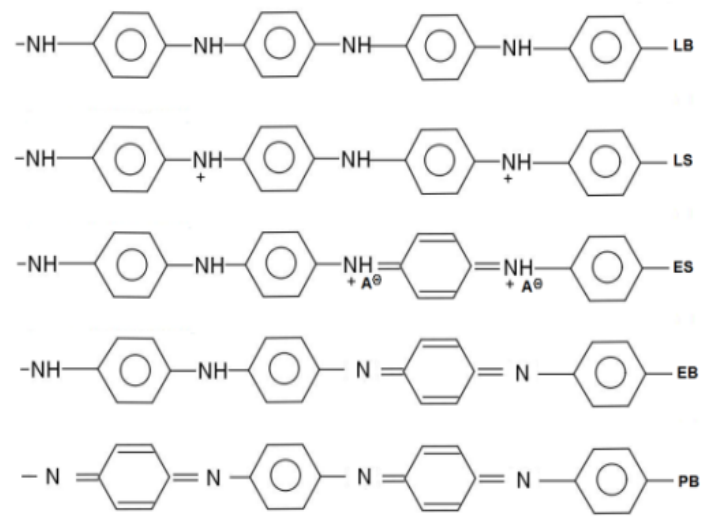

Figure 7. Different forms of polyaniline - LB: leucoemeraldine base; LS: leucoemeraldine salt; ES: emeraldine salt; EB: emeraldine base and PB: pernigraniline base.

Four important aspects can be highlighted for region (II), between 1520 and $1210 \mathrm{~cm}^{-1}$, of the Raman spectra:

a) The Raman spectra of both polyanilines synthesized in this work exhibit bands / peaks that can be associated to C $\mathrm{N}^{+}$bond vibrations of delocalized polaronic structures and polaron segments in the polymer chains[40-43]. The Raman spectra of PAni-HCl present a broad band and two relatively weak peaks in 1347,1330 and $1315 \mathrm{~cm}^{-1}$, respectively, which can be associated to vibrational modes of $\mathrm{C}-\mathrm{N}^{+}$ delocalized polaronic structures. The spectrum of PAni-HCOOH also present a peak in $1372 \mathrm{~cm}^{-1}$, a shoulder in $1327 \mathrm{~cm}^{-1}$, and a broad band in $1304 \mathrm{~cm}^{-1}$, attributed to vibrations of delocalized polaronic structures $\left(\mathrm{C}-\mathrm{N}^{+\bullet}\right)$. However, the relative intensity of the peaks corresponding to $\mathrm{C}-\mathrm{N}^{+\bullet}$ vibrations to the peak corresponding to $\mathrm{C}-\mathrm{H}$ bonds deformation in the ring plane (peak in $\sim 1165 \mathrm{~cm}^{-1}$ ) in the PAni-HCOOH spectrum is higher than similar intensity relation for the same peaks in the spectrum of PAni-HCl. This observation allows concluding that polaron segments are the main constituents of the polymer chain of PAni$\mathrm{HCOOH}$, i.e., the doping degree of $\mathrm{PAni}-\mathrm{HCOOH}$ is higher than that of $\mathrm{PAni}-\mathrm{HCl}$, as was already suggested by the TGA and FT-IR results.

b) The Raman spectra of PAni-HCl presents an intense band in $1486 \mathrm{~cm}^{-1}$ attributed to $\mathrm{C}=\mathrm{N}$ stretching in quinoid units $(\mathrm{Q})[41-46]$ and vibration of imine group[40]. This peak also appears in the Raman spectrum of PAni-HCOOH at $1489 \mathrm{~cm}^{-1}$, but its relative intensity to the peak corresponding to $\mathrm{C}-\mathrm{H}$ bonds deformation in the ring plane (peak in $\sim 1165 \mathrm{~cm}^{-1}$ ) is lower in this last spectrum. This last observation is an additional indication that polaron segments dominate the PAni-HCOOH structure.

c) The bands related to the amine groups appear in the Raman spectra of PAni-HCl as two bands at 1217 and 1264 $\mathrm{cm}^{-1}$. Similar bands are present in the PAni-HCOOH spectra as a weak broad band in $1210 \mathrm{~cm}^{-1}$ and a shoulder in 1278 $\mathrm{cm}^{-1}[45-48]$.

d) The Raman spectrum of PAni-HCl shows a peak with relatively low intensity at $1410 \mathrm{~cm}^{-1}$. This peak has been attributed to $\mathrm{C}-\mathrm{N}$ bonds of tertiary amines on cyclic structures produced during the crosslinking of the polymer[37],[41-44]. It is noteworthy to point out that this peak was not observed in the Raman spectrum of the polyaniline obtained in formic acid, PAni-HCOOH.

The main features of the region corresponding to the stretch modes of $\mathrm{C}=\mathrm{C}$ and $\mathrm{C}-\mathrm{C}$ vibrations in quinoid and semi-quinone (B) (Q) rings are those bands that appear, respectively, in 1587 and $1556 \mathrm{~cm}^{-1}$ in the spectrum of $\mathrm{PAni}-\mathrm{HCl}$, and 1586 and $1566 \mathrm{~cm}^{-1}$ in the spectrum of PAni-HCOOH[39, 46-47]. The Raman spectrum of PAni-HCOOH shows a peak at $1536 \mathrm{~cm}^{-1}$ that is not present in the spectrum of PAni-HCl. This peak has been attributed to deformation of $\mathrm{N}-\mathrm{H}$ bonds [39] and usually appears only in the Raman spectra of polyanilines containing segments bipolaron. This finding reinforces the conclusion that polaron segments dominate the PAni-HCOOH structure synthesized in this work.

\subsection{Electrical Conductivity}

The electrical conductivity values of the polyaniline (PAni-HCl and PAni-HCOOH) are presented in Table 1.

The electrical conductivity of the PAni-HCOOH $(7.51 \mathrm{~S}$ $\left.\mathrm{cm}^{-1}\right)$ is greater than that of the PAni-HCl $\left(0.143 \mathrm{~S} \mathrm{~cm}^{-1}\right)$. This occurs because the oxidation and doping degree of the 
polyaniline doped with formic acid is greater than that of that doped with hydrochloric acid.

Table 1. Electrical conductivity of PAni-HCl and PAni-HCOOH

\begin{tabular}{cc} 
Polyanilines & Electrical Conductivity $\left(\mathrm{S} \mathrm{cm}^{-1}\right)$ \\
PAni-HCl & 0.143 \\
PAni-HCOOH & 7.51 \\
\hline
\end{tabular}

\section{Conclusions}

The thermogravimetric analysis (TGA) in oxidizing atmosphere (air) shows that the absorption of water by the $\mathrm{PAni}-\mathrm{HCl}$ is greater than the $\mathrm{PAni}-\mathrm{HCOOH}$ and also suggests that the doping level of PAni with $\mathrm{HCOOH}$ is higher than that of PAni with $\mathrm{HCl}$. The presence of formic acid as a dopant in the PAni-HCOOH structure contributes for its structure stabilization in oxidative atmosphere and temperature range of $85-215^{\circ} \mathrm{C}$. In non oxidative atmosphere $\left(\mathrm{N}_{2}\right)$, three stages of polymer chain break seems to be involved in the thermal degradation of PAni-HCOOH: break into small fragments in temperatures between 390 and 650 ${ }^{\circ} \mathrm{C}$, with formation of aromatic and substituted aromatic segments, which decarboxylate and graphitize at temperatures around 650 and $700{ }^{\circ} \mathrm{C}$, respectively. In inert atmosphere, the polymer chain of $\mathrm{PAni}-\mathrm{HCl}$, on the other hand, seems to gradually break into more extended aromatic fragments that suffer further decarboxylation and graphitization at temperatures over $700^{\circ} \mathrm{C}$. The DSC results confirm these differences in the thermal degradation mechanism in non oxidative atmosphere of the polymeric chain of both polyanilines, $\mathrm{PAni}-\mathrm{HCl}$ and $\mathrm{PAni}-\mathrm{HCOOH}$, synthesized in this work.

The results of FT-IR spectra show that the doping level of PAni-HCOOH is somewhat higher than that of PAni-HCl. Therefore, these FT-IR results agree with the thermogravimetric analysis (TGA) in oxidizing atmosphere, which also suggest that the doping level of PAni with $\mathrm{HCOOH}$ is higher than that of PAni with $\mathrm{HCl}$.

The Raman results show that both polyanilines present segments of bipolaron structure in the polymer chain, and that the polymeric chain of PAni-HCOOH contains appreciable amount of segments of the more oxidized pernigraniline base form. Therefore, one can say that the oxidation degree of PAni-HCOOH is higher than that of $\mathrm{PAni}-\mathrm{HCl}$ and that polaron segments dominate the PAni-HCOOH structure.

The conductivity measurements showed that the polyaniline synthesized in formic acid medium has higher electrical conductivity than the polyaniline synthesized in of hydrochloric acid medium.

\section{ACKNOWLEDGEMENTS}

The authors thank the Instituto Tecnológico de Aeronáutica (ITA), Conselho Nacional de Desenvolvimento Científico e Tecnológico (CNPq), and Instituto Nacional de Pesquisas Espaciais (INPE) for, respectively, the financial support and help with the Raman spectroscopy analyses.

\section{REFERENCES}

[1] D. E. Tallman, Y. Pae, G.P. Bierwagen, "Conducting Polymers and Corrosion 2: Polianiline on Aluminum Alloys," Corrosion, vol. 56, pp. 401-410, 2000.

[2] D. E. Tallman, G. Spinks, A. Dominis, G.G. Wallace, "Electroactive conducting polymers for corrosion control," Journal of Solid State Electrochemistry, vol. 6, pp. 73-84, Febr. (2002).

[3] K. Shah, J. Iroh, "Electrochemical synthesis and corrosion behavior of poly (n-ethyl aniline) coatings on Al-2024 alloy," Synthetic Metals, vol. 132, pp. 35-41, Dec. (2002).

[4] C. Arbizzani, M. Mastragostino, B. Scrosati, H.S. Nalwa, Handbook of Organic Conductive Molecules and Polymers Wiley, New York, United States of American, vol. 4, Chapter. $11,1997$.

[5] L.H.C. Mattoso, "Polianilinas:síntese, estrutura e propriedades," Química Nova, vol. 19, pp. 388-399, Oct. (1996).

[6] M. Zilberman, G.I Titelman, A. Siegmann, Y. Haba, M. Narkis, D. Alperstein, "Conductive blends of thermally dodecylbenzene sulfonic acid-doped polyaniline with thermoplastic polymers," Journal of Applied Polymer Science, vol. 66, pp. 243, Dec. (1997).

[7] E. W. Paul, A. J. Ricco, M. S. Wrighton, "Resistance of polyaniline films as a function of electrochemical potential and the fabrication of polyaniline-based microelectronic devices," Journal Physical Chemistry, vol 89, pp.1441-1447, (1985).

[8] H. Tsutumi, S. Yamashita, T. Oishi, "Preparation of polyaniline-poly (p-styrenesulfonic acid) composite by post-polymerization and application as positive active material for a rechargeable lithium battery," Journal of Applied Electrochemistry, vol. 27, pp. 477-481, June (1997).

[9] C. K. Chiang, C. R. Fincher, Y. W. Park, A. J. Heeger, H. Shirakawa, E. J. Louis, A. G. MacDiarmid, "Electrical Conductivity in Doped Polyacetylene," Physical Review Letters, vol. 39, pp. 1098-1101, Oct. (1977).

[10] R. A. Zoppi, M. A. De Paoli, "Aplicações Tecnológicas de polímeros condutores: perpectivas atuais," Química Nova, vol. 16, PP. 560-569, (1993).

[11] E. H. Toma, "Ligação Química: Abordagem Clássica Quântica,” Química Nova na Escola, vol. 6, pp. 8-12, (1997).

[12] A. R. Mendoza, F. Corvo, "Outdoor and indoor atmospheric corrosion of non-ferrous metals," Corrosion Science, vol. 42, pp. 1123-1147, Oct. (2000).

[13] N. L. D. Somasiri, A. G. MacDiarmid, "Polyaniline: characterization as a cathode active material in rechargeable batteries in aqueous electrolytes," Journal of Applied Electrochemistry, vol. 18, pp. 92-95, (1988).

[14] P. N. Bartlett, P. R. Birkin, "The application of conducting polymers in biosensors," Synthetic Metals, vol. 61, pp.15-21, April (1993). 
[15] M. Gazard, A. Skotheim, Handbook of Conducting Polymers, Marcel Dekker, United States of American, New York, vol.1, Chapter. 19, (1986).

[16] E. M. Geniès, A. Boyle, M. Lapkowski, C. Tsintavis, "Polyaniline: A historical survey," Synthetic Metals, vol. 36, pp. 139-182, Jan. (1990).

[17] W. -S. Huang, B. D. Humphrey, A. G. MacDiarmid, "Polyaniline, a novel conducting polymer. Morphology and chemistry of its oxidation and reduction in aqueous electrolytes" Journal of the Chemical Society, Faraday Transactions 1: Physical Chemistry in Condensed Phases, vol. 82, pp. 2385-2400, (1986).

[18] S. Stafström, J. L. Brédas, A. J. Epstein, H. S. Woo, D. B. Tanner, W. S. Huang, A. G. MacDiarmid, "Polaron Lattice in Highly Conducting Polyaniline: Theoretical and Optical Studies," Physical Review Letters, vol. 59, pp. 1464-1467, (1987).

[19] A. G. MacDiarmid, A. J. Epstein, "Polyanilines: a novel class of conducting polymers," Faraday Discussions of the Chemical Society," vol. 88, pp. 317-332, (1989).

[20] S. Tao, B. Hong, Z. Kerong, "An infrared and Raman spectroscopic study of polyanilines co-doped with metal ions and $\mathrm{H}+$,'Spectrochimica Acta Part A: Molecular and Biomolecular Spectrocopy, vol. 66, pp. 1364-1368, (2007).

[21] L. Brožová, P. Holler, J. Kovářová, J. Stejskal, M. Trchová, "The stability of polyaniline in strongly alkaline or acidic aqueous media," Polymer Degradation and Stability, vol. 93, pp. 592, January (2008).

[22] T. Chen, C. Dong, X. Li, J. Gao, "Thermal degradation mechanism of dodecylbenzene sulfonic acid- hydrochloric acid co-doped polyaniline," Polymer Degradation and Stability, vol. 94, pp. 1788-1794, (2009).

[23] A. G. MacDiarmid, J. C. Chiang, W. S. Huang, B. D. Humphery, N. L. D. Somasiri, "Polyaniline: protonic acid doping to the metallic regime," Molecular Crystals and Liquid Crystals, vol. 25, pp. 309-318, (1985).

[24] R. Faez, C. Reis, P. S. Freitas, O. K. Kosima, G. Ruggeri, M. A. De Paoli, "Polímeros Condutores," Química Nova na Escola., vol. 11, pp. 13-18, (2000).

[25] A. Dan, P. K. Sengupta, "Synthesis and characterization of polyaniline prepared in formic acid medium," Journal of Applied Polymer Science, vol. 91, pp. 991-999, (2004).

[26] J. Yue, A. J. Epstein, Z. Zhong, P. K. Gallagher, A. G. MacDiarmid, " Thermal stabilities of polyanilines," Synthetic Metals, vol. 41, pp. 765-768, (1991)

[27] Y. Wei, G. W. Jang, K. F. Hsueh, A. G. MacDiarmid, A. J. Epstein, "Thermal transitions and mechanical properties of films of chemically prepared polyaniline," Polymer, vol. 33, pp. 314- 322, (1992)

[28] N, Chandrakanthi, M. A. Careem, "Thermal Stability Polyaniline," Polymer Bulletin, vol. 44, pp. 101-108, (2000).

[29] K. Luo, N. Shi, C. Sun, "Thermal transition of electrochemically synthesized polyaniline," Polymer Degradation and Stability, vol. 91, pp. 2660-2664, (2006).

[30] S. Bhadra, D. Khastgir, "Extrinsic and intrinsic structural change during heat treatment of polyaniline," vol. 92, pp.
1094-1099, (2008).

[31] X. R. Zeng, T. M. Ko, "Structures and properties of chemically reduced polyanilines," vol. 39, pp. 1187-1195, (1998).

[32] E. Erdem, M. Karakısla, M. Saçak, " The chemical synthesis of conductive polyaniline doped with dicarboxylic acids," European Polymer Journal, vol. 40, pp. 785-791, (2004).

[33] R. Mathew, D. Yang, B. R. Mattes, M. P. Espe, " Effect of Elevated Temperature on the Reactivity and Structure of Polyaniline," Macromolecules, vol. 35, pp. 7575-7581, (2002).

[34] Mosqueda, Y.; Perez-Capp, E.; Arana, J.; Longo, E.; Ries, A.; Cilense, M.; Nascente, P.A.P.; Aranda, P.; Ruiz-Hitzky, E.; J. Sol. Stat. Chem. 2006, 179, 308.

[35] S. Palaniappan, B. H. J. Narayana, " Temperature effect on conducting polyaniline salts: Thermal and spectral studies," Journal of Polymer Science Part A: Polymer Chemistry, vol. 32, pp. 2431-2436, (1994).

[36] I. Dumitrescu, C.-A. Nicolae, A. M. Mocioiu, R. A. Gabor, M. Grigorescu, M. Mihailescu, "Synthesis and characterization of conductive polymers with enhanced solubility," U.P.B. Scientific Buletin Series A, vol.71, pp. 63-72, (2009).

[37] R. Ansari, M. B. Keivani, "Polyaniline Conducting Electroactive Polymers: Thermal and Environmental Stability Studies," E-Journal of Chemistry, vol. 3, pp. 202-217, Oct. (2006).

[38] T. Abdiryim, Z. Xiao-Gang, R. Jamal, "Comparative studies of solid-state synthesized polyaniline doped with inorganic acids," Materials Chemistry and Physics, vol. 90, pp. 367-372, (2005).

[39] M. C. Bernard, H. L. Goff, "Quantitative Characterization of Polyaniline Films Using Raman Spectroscopy I: Polaron Lattice and Bipolaron,"Electrochimica Acta, vol. 52, pp. 595-603, (2006).

[40] M. C. Bernard, S. I. C. Torresi, H. L. Goff, "In situ Raman study of sulfonate-doped polyaniline," Electrochimica Acta, vol. 44, pp. 1989-1997, (1999).

[41] M. G. Nascimento, M. L. A. Temperini, "Studies on the resonance Raman spectra of polyaniline obtained with near-IR excitation,” Journal Raman Spectroscopy, vol. 39, pp. 772-778, July (2008).

[42] I. Sedenková, M. Trchová, J. Stejskal, "Thermal degradation of polyaniline films prepared in solutions of strong and weak acids and in water - FTIR and Raman spectroscopy studies," vol. 93, pp. 2147-2157, (2008).

[43] J. E. P. Silva, D. L. A. Faria, S. I. C. Torresi, M. L. A. Temperini, "Influence of Thermal Treatment on Doped Polyaniline Studied by Resonance Raman Spectroscopy," vol. 33, pp. 3077-3083, (2000).

[44] G. Niaura, R. Mazeikiené, A. Malinauskas, "Structural changes in conducting form of polyaniline upon ring sulfonation as deduced by near infrared resonance Raman spectroscopy," vol. 145, pp. 105-112, (2004).

[45] M. Cochet, G. Louarn, S. Quillard, J. Buisson, S. Lefrant, "Theoretical and experimental vibrational study of emeraldine in salt form. Part II," Journal Raman Spectroscopy, vol. 31, pp. 1041-1049, (2000). 
[46] G. Louarn, M. Lapkowski, S. Quillard, A. Pron, J. P. Buisson, S. Lefrant, "Vibrational Properties of Polyaniline-Isotope Effects,"Journal Physical Chemistry, vol. 100, pp. 6998-7006, (1996).

[47] M. I. Boyer, S. Quillard, E. Rebourt, G. Louarn, J. P. Buisson, A. Monkman, "Vibrational Analysis of Polyaniline: A Model
Compound Approach," Journal Physical Chemistry B, vol. 102, pp. 7382-7392, Aug. (1998).

[48] A. Buzarovska, I. Arsova, L. Arsov, "Electrochemical synthesis of poly (2-methyl aniline): electrochemical and spectroscopic characterization," Journal of the Serbian Chemical Society, vol. 66, pp. 27-37, Oct. (2001). 